\title{
Fundamentos para los estudios organizacionales: aportes del pensamiento crítico suramericano
}

\author{
Foundations for the organizational studies: contributions of South American critical \\ thinking
}

\section{Fundamentos para os estudos organizacionais: contribuições do pensamento crítico sul- americano}

Hugo Chumbita ${ }^{1}$

Instituto Nacional de Revisionismo Histórico Argentino e Iberoamericano Manuel Dorrego, Buenos Aires, Argentina

\begin{abstract}
Resumen
Frente a la visión eurocéntrica predominante y la influencia de los modelos de las naciones hegemónicas en los estudios y las reformas de la administración pública, se plantea otra perspectiva, basada en el pensamiento crítico sobre las raíces históricas de la dependencia y la problemática actual de las sociedades suramericanas. El continuo proceso de occidentalización de América, a través de la penetración colonial y neocolonial, impuso los intereses y la cultura de los países del centro del mundo, provocando efectos de refracción, resistencia y adaptación. Las consecuencias de este conflicto étnico están en el origen de la devaluación del orden legal, la marginalidad y anomia social. La revolución independentista continental, que reconoció derechos a las mayorías, fue desvirtuada por las oligarquías, reproduciendo las desigualdades y las condiciones de otra forma de dependencia en la etapa del neocolonialismo capitalista. Los movimientos políticos nacional-populares del siglo XX promovieron una conciencia crítica, que tuvo su correlato en las corrientes alternativas en la filosofía y las ciencias sociales, pero sufrieron una regresión ante la ofensiva neoliberal. El cuadro sociocultural suramericano muestra una insuficiente legitimación del Estado, factores de desorden social y disfunciones en la gestión del sector público; lo cual requiere repensar el marco teórico de los estudios organizacionales, potenciar la comunicación de experiencias entre científicos e intelectuales de la región, revisar los proyectos de reforma inspirados en modelos exógenos y diseñar nuevos modos de intervención para promover la participación popular, apuntando al horizonte de la integración y la emancipación de nuestros países.
\end{abstract}

Palabras clave: Pensamiento Crítico. Estudios Organizacionales. Eurocentrismo. Dependencia.

\begin{abstract}
Given the dominant Eurocentric view and the influence of models from hegemonic nations on studies and public administration reforms, another perspective is introduced, having critical thinking about the historical roots of dependency and the current problems of South American societies as a basis. The continuous process of Westernization of America, through the colonial and neocolonial penetration, imposed the interests and culture of countries from the world's center, causing effects of refraction, resistance, and adaptation. The consequences of this ethnic conflict are at the origin of devaluation of legal order, marginality, and social anomy. The continental separatist revolution, which recognized rights to the majorities, was tainted by oligarchies, reproducing the inequalities and conditions of another way of dependency at the stage of capitalist neocolonialism. The national-popular political movements of the 20th century have promoted a
\end{abstract}

Artículo enviado en 17 de diciembre de 2013 y aprobado para publicación en 24 de noviembre de 2014 .

DOI: http://dx.doi.org/10.1590/1679-395114074

1 Doctor en Derecho; Ex Profesor e investigador de la Universidad de Buenos Aires y del Instituto Nacional de la Administración Pública; Miembro del Instituto Nacional de Revisionismo Histórico Argentino e Iberoamericano Manuel Dorrego. Dirección: Malabia 2330, (CP 1425) Buenos Aires, Argentina. E-mail: hugochumbita@hotmail.com 
critical consciousness, which had its counterpart among alternative currents in philosophy and social sciences, but they suffered a regression in face of the neoliberal offensive. The South American sociocultural framework shows a lack of State legitimacy, social disorder factors, and dysfunction in public sector management; this requires rethinking the theoretical framework of organizational studies, encouraging the communication of experiences among scientists and intellectuals from the region, reviewing the reform projects inspired by exogenous models, and designing new ways of intervention to promote popular participation, aiming at the horizon of integration and emancipation of our countries.

Keywords: Critical Thinking. Organizational Studies. Eurocentrism. Dependency.

\section{Resumo}

Diante da visão eurocêntrica dominante e da influência dos modelos das nações hegemônicas nos estudos e nas reformas da administração pública, apresenta-se outra perspectiva, baseada no pensamento crítico acerca das raízes históricas da dependência e da problemática atual das sociedades sul-americanas. O contínuo processo de ocidentalização da América, por meio da penetração colonial e neocolonial, impôs os interesses e a cultura dos países do centro do mundo, causando efeitos de refração, resistência e adaptação. As consequências desse conflito étnico estão na origem da desvalorização da ordem jurídica, da marginalidade e da anomia social. A revolução independentista continental, com reconhecimento de direitos às maiorias, foi desvirtuada pelas oligarquias, reproduzindo as desigualdades e as condições de outra forma de dependência na etapa do neocolonialismo capitalista. Os movimentos políticos nacional-populares do século XX promoveram uma consciência crítica, que teve sua contrapartida nas correntes alternativas na filosofia e nas ciências sociais, mas sofreu uma regressão diante da ofensiva neoliberal. $O$ quadro sociocultural sul-americano mostra uma insuficiente legitimação do Estado, fatores de desordem social e disfunções na gestão do setor público; o que exige repensar o quadro teórico dos estudos organizacionais, fomentar a comunicação de experiências entre cientistas e intelectuais da região, rever os projetos de reforma inspirados em modelos exógenos e projetar novas formas de intervenção para promover a participação popular, visando ao horizonte da integração e da emancipação de nossos países.

Palavras-chave: Pensamento Crítico. Estudos Organizacionais. Eurocentrismo. Dependência.

\section{Introducción}

En el área de las ciencias sociales es sensible el predominio de una visión eurocéntrica, arraigada en los sistemas de enseñanza de estas disciplinas, que concibe los procesos históricos de los países latinoamericanos o suramericanos ${ }^{2}$ como epifenómenos de los acontecimientos de la civilización occidental, considerándolos como una extensión y reproducción "natural" de las instituciones de los países "desarrollados". Esta concepción tiende por un lado a diluir la conciencia de la comunidad de nuestros pueblos, entre los cuales subsiste una lamentable falta de comunicación, y por otro lado a dirigir la atención hacia los lazos con las naciones del polo noratlántico a las que se toma como referencia.

En el campo de los estudios organizacionales, las propuestas de análisis, diagnóstico e intervención suelen basarse en los modelos de funcionamiento del Estado y la correspondencia entre éste y los actores sociales que se observan en aquellas naciones. Esta forma de dependencia intelectual se refuerza y se profundiza en el diseño de las políticas, la legislación y la administración del sector público, debido al fenómeno general de "internacionalización de los estados nacionales" (OSZLAK, 2006), y en particular por la gravitación de organismos, acuerdos, entidades financieras, agencias de cooperación y empresas multinacionales que patrocinan proyectos de evaluación o de reformas siguiendo las pautas experimentadas en los países "más

${ }^{2}$ Si bien el nombre América Latina es de uso corriente, se trata de un concepto discutible por su remisión excluyente a una particular matriz cultural europea, por lo cual en este trabajo optamos por la denominación Suramérica, entendiendo abarcar a todos los países situados al sur de Estados Unidos. 
adelantados", así como también por la creciente influencia norteamericana en las escuelas de administración (BARROS y PÁDUA CARRIERI, 2013).

Frente a este panorama, después de trabajar algunos años en investigaciones sobre la administración nacional en la Argentina, lo que me permitió conocer la labor de varios colegas en otros países de la región, el propósito del presente texto es plantear la necesidad de enmarcar el estudio de las organizaciones y la gestión pública en un cuadro sociocultural que aproveche y actualice el pensamiento crítico suramericano; un vasto caudal de producción teórica e indagaciones socio-históricas, del cual menciono, a riesgo de inevitables omisiones, los textos que concuerdan o pueden servir de apoyo a mis propias afirmaciones.

Publicaciones recientes muestran la discusión de algunas cuestiones atingentes por investigadores brasileños dedicados a los estudios organizacionales, que vinculan la teoría crítica en este campo con el marxismo occidental frankfurtiano (FARIA, 2009), o plantean una relación dialógica con la corriente oriental de estudios poscoloniales, y también recusan el radicalismo marxista desde una visión ecléctica o reformista (REIS ROSA y ALCADIPANI, 2013). Es oportuno aclarar por lo tanto que, en la interpretación que desarrollamos aquí, el pensamiento crítico suramericano comprende la obra multidisciplinaria y ensayística de un amplio espectro de autores de nuestros países - sin excluir las contribuciones de estudiosos de otras latitudes-, que rescataron las intuiciones originales del liberalismo revolucionario y se identifican en diversas posiciones ideológicas entre el marxismo, el nacionalismo, el cristianismo y la izquierda democrática, entre los cuales me refiero especialmente a los que contemplan el conjunto de la región con una concepción americanista integradora.

Un eje principal de este pensamiento crítico es la caracterización de las relaciones asimétricas o de dominación de las grandes potencias en diversos ámbitos de nuestras sociedades. A partir de allí se ha procurado entender la evolución de esta parte del mundo cuestionando la concepción unilineal del progreso según el modelo y los valores de las naciones hegemónicas, para explicar el pasado y el presente de los estados suramericanos desde un punto de vista situado en su realidad específica, atendiendo a las demandas de los pueblos que se manifiestan en la historia de sus grandes movilizaciones políticas y sociales (HERNÁNDEZ ARREGUI, 1957; ZEA, 1971; PÉREZ LINDO, 1998).

Contra la supuesta neutralidad u objetividad que postula el cientificismo o el relativismo académico, los intelectuales que abrieron este camino asumían que el conocimiento social es básicamente un espacio de confrontación entre diversas concepciones del mundo, en cuyos extremos se tensan las ideas propiciadas por los poderes económicos del capitalismo internacional, y la búsqueda de alternativas congruentes con las necesidades e intereses de las mayorías populares.

No se trata de rechazar los aportes humanistas de matriz europea, ni sus extraordinarios progresos tecnológicos, ni el ideal de llegar a una comunidad universal del conocimiento. Pero en los conflictos que recorren la historia americana a partir de las etapas de colonización y recolonización, en el nudo de sus contradicciones sociales, subyace un profundo antagonismo, teñido por el entrecruzamiento de culturas, que reclama ser resuelto definiendo nuestra propia identidad, y la toma de posición política o intelectual sobre los problemas de fondo resulta inseparable del modo de comprender el dilema entre la autodeterminación y la dependencia (ROIG, 1981; MONTIEL, 2000; GUADARRAMA, 2002).

Este enfoque epistemológico, que ha fructificado en el campo de la filosofía, la historia y las ciencias sociales, requiere tener en cuenta un conjunto de temas y problemas encadenados que aquí sintetizamos en los siguientes puntos: la occidentalización de América y los efectos de resistencia y adaptación; el conflicto étnico y sus consecuencias; las contradicciones del proceso de emancipación continental; la concientización que estimularon los movimientos nacional-populares; y las resultantes actuales de desorden institucional y organizacional, frente a lo cual proponemos un giro conceptual en nuestras propias conciencias, que es necesario transmitir a través de la enseñanza y que debe servir para elaborar los instrumentos de una acción transformadora. 


\section{La occidentalización de América}

Nuestra historia en la época moderna y contemporánea se puede resumir como un proceso de integración a Occidente, es decir, al sistema económico, social y político de las naciones del oeste de Europa, donde se fue constituyendo el centro del mercado capitalista mundial, sobre la base de la explotación colonialista que realizaron en éste y otros continentes.

Las sociedades originarias fueron truncadas violentamente en sus propias posibilidades de desarrollo. A lo largo de cinco siglos, se impusieron las instituciones de la civilización occidental -la propiedad privada, el mercantilismo, el capitalismo, las formas de Estado y las tecnologías generadas por los países centrales-, en un mundo "nuevo" (para los europeos), a través de sucesivas etapas: la conquista y la colonización por los imperios que constituían la vanguardia europea, España y Portugal; el neocolonialismo de las potencias noratlánticas - preponderantemente Inglaterra y luego Estados Unidos - y la reciente globalización o mundialización de signo neoliberal.

Cada una de estas fases conllevó notables adelantos materiales y la posibilidad de integrar a las poblaciones en una escala más amplia de civilización, pero ahondaron y complejizaron los lazos de dependencia, acarreando de manera recurrente efectos disruptores y enormes costos humanos para los países subordinados.

Los proyectos que se desplegaron han sido caracterizados generalmente como de "modernización", denominación engañosa en tanto presupone la unidireccionalidad del progreso histórico, el cual sólo sería concebible conforme al patrón occidental; y en todo caso resultó una "modernización selectiva", donde las transformaciones se circunscribían a determinados ámbitos y se realizaron en la medida de la conveniencia de los centros directrices. La comprensión de estos procesos de dimensión planetaria requiere tener en cuenta la dicotomía que se configura a partir de la revolución industrial entre centro y periferia (SUNKEL y PAZ, 1973), su necesaria interrelación y los efectos que se han caracterizado en términos de "desarrollo desigual" (RIBEIRO, 1972).

Asimismo es evidente que la penetración de la cultura occidental europea en la periferia se fue profundizando históricamente, desde la ocupación territorial y el control exterior y físico sobre las personas y los recursos naturales, hasta las variantes más sutiles y complejas de hegemonía a través de la influencia en los hábitos de consumo, la difusión de la información y las formas de elaboración y validación del conocimiento.

Como sugiere uno de los autores que contribuyeron a dar consistencia teórica a la corriente del pensamiento crítico (PUIGGRÓS, 1974, p. 5 y ss), para comprender esta realidad no se trata de ver sólo las fuerzas o causas externas, sino también las causas internas a través de las cuales aquéllas inciden, y cómo la dinámica histórica transforma e interioriza el impacto de las causas externas.

\section{Refracción, resistencia y adaptación}

Tanto en las proyecciones materiales del traslado de las instituciones y la tecnología económica del capitalismo, como en sus expresiones en la esfera de las ideologías y el discurso, el trasplante del centro a la periferia provoca un fenómeno de "refracción", es decir, de distorsión o desvío (semejante a la refracción de la luz o el sonido al pasar de un medio a otro diferente), de modo que la reproducción material o la importación ideológica arroja por lo común un resultado distinto al del original. Esta comprobación es fundamental para entender la naturaleza particular de la occidentalización de nuestros países y las disparidades, a veces sumamente chocantes, entre estructuras y doctrinas que se suponen homólogas y funcionan de manera diferente en el escenario suramericano (CHUMBITA, 2013, p. 424-426). 
Por otra parte, diversas vertientes en la línea del pensamiento crítico han puesto el acento en mostrar múltiples formas de resistencia a las redes de subordinación (ARGUMEDO, 2004, p. 15 y ss), aunque también corresponde tener en cuenta los modos de adaptación deliberada o forzosa de las novedades introducidas por los factores exógenos (BAGÚ, 1949).

La experiencia histórica proporciona abundantes ejemplos de la recepción ambivalente y conflictiva de la dominación colonial y neocolonial: ésta se estableció siempre con el concurso de determinados sectores que obraron como agentes y aliados en el interior de nuestros países; y del otro lado, las poblaciones autóctonas y las expresiones políticas que las representaban se levantaron para defender sus propios intereses frente a las oleadas "modernizadoras".

El reverso del largo proceso de occidentalización ha sido y es la resistencia popular -de los grupos étnicos originarios o trasplantados, y luego de sus descendientes de otras generaciones, progresivamente mestizados- frente a la perspectiva de ser asimilados, aniquilados o sojuzgados por la violencia de los sucesivos proyectos que se impusieron en cada etapa, destruyendo los resultados de la etapa anterior. Así como las mayores civilizaciones indoamericanas fueron abatidas por la conquista española, las sociedades hispano-criollas que emergieron de la lucha contra el estatuto colonial fueron avasalladas en el siglo XIX por la reconfiguración del capitalismo dependiente, y los ensayos del siglo XX para regenerar la autonomía de las repúblicas sobre las bases de la industrialización y la democratización fueron en gran parte frustrados por la reacción global del neoliberalismo.

Claro que las instituciones y técnicas introducidas por los dominadores no son desechables en sí mismas, sino en cualquier caso cuestionables por el modo y el propósito con que se instrumentan. Los pueblos subordinados acogieron siempre en todos los órdenes de su existencia social las innovaciones compatibles con su bienestar, y se esforzaron por organizar alternativas propias de desarrollo, adaptando los aportes que consideraban más valiosos de la cultura occidental, desde la lengua y la imprenta hasta el maquinismo. De la misma manera, uno de los desafíos actuales es apropiar las herramientas de la informatización y las ciencias para superar la condición de mercados o receptores pasivos y cimentar un camino civilizatorio a la medida de nuestras necesidades materiales y humanas (COLOMBRES, 2008, p. 179 y ss).

Un análisis completo de las causas externas e internas, atendiendo al papel de los sectores o grupos de interés y las propuestas ideológicas que actúan consciente o inconscientemente en el mismo sentido que las presiones imperialistas, indica que los conflictos, más que en el terreno de las confrontaciones internacionales, tienden a dirimirse dentro de nuestras sociedades, y en la actual "era de la información" o de la comunicación, cada vez más en el nivel de la superestructura cultural.

\section{El conflicto étnico y las consecuencias sociales}

En América, la centralidad del conflicto étnico deviene de las supervivencias del pasado colonial y sus secuelas, en el sentido de la colisión de la cultura dominante con la cultura o subculturas subordinadas. Fundado en las diferencias de razas y animado por motivaciones claramente políticas y clasistas, este conflicto comenzó oponiendo a los colonizadores con los colonizados, y con la evolución del colosal mestizaje operado en nuestro continente -fenómeno de magnitudes sin parangón en la historia mundial- se fue tornando, más allá de las categorías y las apariencias raciales, en una cuestión problemática, una grieta social y cultural que plantea una opción de identidad (MONTIEL, 2000).

En la etapa colonial hispánica, las desigualdades de la sociedad indiana fueron moldeadas por el régimen de castas, bajo la institución de la "pureza de sangre" (CANESSA, 2000). Este canon arbitrario era funcional para naturalizar la supremacía de los conquistadores "blancos" y justificar el sometimiento de los conquistados al esclavismo, la mita, la encomienda, el "pongaje" y otros sistemas de compulsión laboral que se prolongaron en los tiempos poscoloniales, mediante los cuales se explotó, marginó e "inferiorizó" al 
conjunto -absolutamente mayoritario- de la población indígena, africana y mestiza, privada en diversos grados de derechos civiles y políticos (ROSENBLAT, 1954).

La consiguiente postración social y cultural de los oprimidos sirvió a su vez de fundamento a los prejuicios discriminatorios, la descalificación y el desprecio hacia las masas nativas que constituyeron la mano de obra del capitalismo dependiente en el período de las repúblicas oligárquicas, y esas rémoras mentales han subsistido de manera abierta o encubierta hasta nuestros días (SAGRERA, 1974; PAZ, 1994; FERNANDES, 2008).

Por otra parte, las reacciones de autodefensa de las castas sometidas generaron, a la par de los reclamos orgánicos y las periódicas insurrecciones, fenómenos de marginalidad o de apartamiento de la ley calificados como bandolerismo, y prácticas menos ostensibles de "resistencia cotidiana" a la sujeción a los amos o la explotación laboral. Los comportamientos de trabajo a desgano, "arrastrando los pies", con descuido, causando daños a las instalaciones, percibidos por los patrones como indolencia, haraganería o malicia -que incluso dieron pie a las teorizaciones de los científicos positivistas sobre la "pereza" sudamericana (TERÁN, 1987), adquieren sin embargo otro sentido a la luz de los estudios que los caracterizan como formas de resistencia social y anticolonial (STERN, 1987).

Los factores y actitudes reluctantes a la autoridad y al trabajo enajenado, que sin duda socavaron las estructuras productivas, perduraron en el tiempo y alimentaron en las clases populares pautas culturales muy difundidas de rechazo a la ley, que están en la base de un fenómeno típico de anomia o desorden normativo en la sociedad (CHUMBITA, 2000).

Estas prácticas también son visibles en el comportamiento de las clases dirigentes, desde la época colonial, cuando por ejemplo los edictos reales de protección a los indios y los que de algún modo contrariaban los intereses patronales eran recibidos por virreyes, regidores y oidores besando el sello de Su Majestad y declarando "se acata pero no se cumple". El divorcio entre el Derecho nominal y la realidad de la sociedad civil generado con la implantación del coloniaje hispánico no hizo más que agravarse, bajo otras formas, en el período de las repúblicas aparentemente independientes (GARCÍA, 1998).

\section{El proyecto emancipador y su desvirtuación}

Propiciado por las condiciones que creó la revolución burguesa mundial, el movimiento independentista de las colonias españolas postulaba construir una sociedad política de ciudadanos iguales, en la cual podían alcanzar su liberación todos los grupos oprimidos, con el liderazgo de una generación de revolucionarios que intentó traducir sus demandas (R. PUIGGRÓS, 1971; TRÍAS, 1957; CHUMBITA, 2010).

Sin embargo, la participación de los indios, los negros y las masas rurales fue restringida, y las nuevas capas dirigentes se dividieron entre los jefes o caudillos solidarios con los estratos populares y los círculos elitistas herederos de los antiguos privilegios de los conquistadores. Esta contradicción derivó en la constitución de las repúblicas oligárquicas que, no obstante las diferencias aparentes con el proceso brasileño de transición del Imperio a la república, coincidieron con éste en abrir las puertas a la penetración mercantil de las potencias capitalistas. Ante la debilidad y las rivalidades entre los estados en los que se fragmentó el continente iberoamericano, el neocolonialismo reprodujo las condiciones de subordinación económica y cultural, a la par del sometimiento y el despojo a las poblaciones autóctonas que llevaron adelante las elites locales.

En la era de las oligarquías, el proyecto de la emancipación fue desvirtuado por el Estado liberal y desfigurado por los sistemas educativos oficiales. El liberalismo revolucionario, vaciado de sus contenidos igualitarios e integradores, fue reducido a la doctrina económica del librecambio y a una ideología positivista centrada en el espejismo de la "civilización" - la cultura de la raza blanca europea contra la barbarie americana-, que sustituía la justificación del salvacionismo religioso por un catecismo científico, sin alterar 
sustancialmente la mentalidad colonial y racista (ZEA, 1980; TERÁN, 1987; FERNÁNDEZ RETAMAR, 1999).

La concepción eurocéntrica llevó a imitar superficialmente las instituciones jurídicas que en el Viejo Mundo surgían de una larga evolución y sedimentación, pero que en América resultaban en gran medida inadecuadas o inaplicables, y por lo tanto se distorsionaron en sus versiones concretas y sus efectos reales. Los principios representativos, los derechos políticos y las libertades civiles se trastocaban en dictaduras, fraude electoral y autoritarismo. Las leyes copiadas de los modelos europeos eran sistemáticamente burladas: según un refrán criollo, "hecha la ley, hecha la trampa"; como ejemplifica un autor francés (ROUQUIÉ, 1990), en Brasil, bajo las presiones británicas, la ley se hacía "para inglês ver" (para que lo vea el inglés), y en Colombia se decía que "la justicia es para los que llevan ruana" (los campesinos). En todo caso, la ley era "para el enemigo", y los jueces aplicaban su rigor a los transgresores de las clases bajas. El mayor ideólogo de la europeización de América (SARMIENTO, 1853), lo expresó claramente: "una constitución no es regla de conducta pública para todos los hombres. La constitución de las masas populares son las leyes ordinarias, los jueces que las aplican y la policía de seguridad. Son las clases educadas las que necesitan una constitución que asegure las libertades de acción y de pensamiento".

La mentalidad europeísta de las elites propugnó la subordinación al "primer mundo" como fuente de toda sabiduría y prosperidad, manteniendo el aislamiento e incluso la hostilidad entre nuestras repúblicas. Consiguientemente, la adopción del dogma del libre comercio y la apertura a los capitales externos configuraron las estructuras productivas extravertidas, que sometieron la actividad económica a los dictados cambiantes e imprevisibles del mercado internacional (GALEANO, 1972; FRANK, 1973).

El credo "civilizador" eurocéntrico infundió en el aparato cultural y educativo los paradigmas científicos y tecnológicos occidentales, estructurando la enseñanza según los estrictos moldes de forma y contenido de las naciones rectoras; y en cuanto a las versiones escolares de la historia de cada país - ignorando las de los vecinos del continente -, su marcado sesgo elitista tendió a desconocer la tradición de las luchas populares por la emancipación (HERNÁNDEZ ARREGUI, 1957; PUIGGRÓS, 1980).

\section{Movimientos populares y conciencia crítica}

Las guerras y las crisis mundiales del siglo $\mathrm{XX}$, que abrieron paso a diversos ensayos de transformaciones socialistas, alentaron la emergencia de los movimientos de base obrera y campesina -como la Revolución Mexicana, los gobiernos nacionales-populares del varguismo en Brasil y del peronismo en Argentina, el aprismo peruano, la Revolución Cubana- que bregaron por recuperar el sentido emancipador de la causa de la independencia, expresando de diversas maneras los proyectos de liberación nacional y social, replanteando los cauces institucionales democráticos y proponiendo avanzar en la integración de una gran nación suramericana (RAMOS, 1968).

La extensión de estos movimientos tropezó con las reacciones imperialistas, con la secular incomunicación de nuestros pueblos y con las incomprensiones recíprocas resultantes de tradiciones político-ideológicas disímiles en cada país. Los proyectos democratizadores encontraron sus límites en las estructuras dependientes de estas sociedades y en las relaciones de fuerza adversas dentro del sistema capitalista internacional; pero promovieron una renovación del pensamiento crítico, que impugnaba el colonialismo cultural y retomaba la tarea de definir un rumbo centrado en las capacidades endógenas del continente.

Estas proposiciones permiten entender a los países suramericanos como un conjunto entrelazado por conflictos y dilemas coincidentes, en los que se viven variantes del mismo proceso histórico; un marco identitario que reclama la solidaridad entre sus partes. Rescatando los ideales originarios de los libertadores -Bolívar, San Martín, O'Higgins, Artigas, Morazán-, las tesis que enlazaban la historia y el destino común de nuestra América fueron anticipadas por algunos escritores y políticos del modernismo hispanoamericano, 
Rubén Darío, Enrique Rodó, José Vasconcelos, Manuel Ugarte, Blanco Fombona, y por las propuestas revolucionarias que predicaron Martí, Mariátegui y Haya de la Torre (BIAGINI, 2000).

Aquellos precursores inspiraron las obras de la generación intelectual que, desde diversos ángulos del nacionalismo de izquierda, trazaron una revisión histórica caracterizando la penetración imperialista y sus proyecciones en el entramado socioeconómico, político y cultural: Hernández Arregui, Abelardo Ramos, Rodolfo Puiggrós, Vivian Trías, Leopoldo Zea, Darcy Ribeiro y otros, confluyendo con los ensayos filosóficos de Augusto Salazar Bondy, Rodolfo Agoglia, Arturo Andrés Roig, las indagaciones sobre los ancestros americanos de José María Arguedas, Bonfill Batalla, Rodolfo Kusch, y las propuestas pedagógicas de Paulo Freire, que estimularon la proliferación del pensamiento crítico en los medios universitarios.

En un plano de elaboración teórica e investigación económica, la corriente estructuralista que profundizó los planteos de la CEPAL, Celso Furtado, Octavio Ianni, Enzo Faletto, Osvaldo Sunkel, Pedro Paz, entre otros economistas y sociólogos, discutieron las categorías del desarrollismo tecnocrático para explicar el cuadro vertebral del subdesarrollo en los términos de la teoría de la dependencia (SUNKEL y PAZ, 1973; DOS SANTOS, 1978). En el terreno de la reflexión filosófica, Enrique Dussel, Gustavo Gutiérrez, Leonardo Boff y otros pensadores de la teología de la liberación, tradujeron desde el cristianismo militante la visión regeneracionista suramericana.

A la par de los textos que historiaron y racionalizaron el legado de las luchas emancipatorias, las pasiones del pasado y del presente americano se reflejaban en el auge de una literatura que recreó el lenguaje, la vivencia y la memoria de las experiencias colectivas: Asturias, Neruda, Uslar Pietri, Carpentier, Amado, Rulfo, García Márquez, Scorza, Viñas, Walsh, Roa Bastos et al., escritores que contribuyeron, junto a incontables producciones en las demás ramas artísticas, a ahondar la revelación del drama de los pueblos insurgentes.

\section{Desorden constitucional y problemas organizacionales}

Un analista europeo que percibió claramente la contradicción entre el orden jurídico formal y la vida social en nuestros países, situados en el "Extremo Occidente" pero con una herencia distinta por su raíz colonial (ROUQUIÉ, 1990, p. 96-98), aconsejaba dejar de lado "las ilusiones etnocéntricas" para "aprehender las distorsiones sufridas por las instituciones tomadas a préstamo", ya que "hay un abismo entre las constituciones escritas y las constituciones vividas". Estas distorsiones "casi esquizofrénicas" son atribuibles a la incongruencia de los principios de igualdad jurídica de los ciudadanos con la distribución real del poder en la sociedad, de modo que "la verticalidad de las relaciones sociales y la brecha a veces pasmosa entre las ideologías institucionales y las conductas sociales dan lugar a una verdadera cultura de las apariencias".

El Estado, controlado durante demasiado tiempo por los grupos oligárquicos, debilitada su legitimidad en la masa de la población, tropieza con una tradición de rechazo a la ley, con arraigadas prevenciones hacia los órganos del aparato político, judicial y administrativo. El des-orden jurídico de las repúblicas suramericanas tiene su origen en la desconfianza de los gobernados hacia las instituciones impostadas, ajenas a la propia experiencia histórica y, en las prolongadas etapas de manipulación de los resortes del poder legal por los gobernantes, desvirtuadas para servir a los objetivos de las minorías.

El ciclo reciente de los regímenes militares, auspiciados por la doctrina norteamericana de la guerra fría y la "seguridad nacional", exacerbó esas consecuencias al quebrar los precarios ordenamientos constitucionales y consumar la violación de los derechos humanos más elementales bajo pretexto de "salvar la libertad" o "preservar la república". La represión ideológica y la ofensiva neoliberal, que coincidieron con el derrumbe del campo comunista, produjeron una regresión en los avances del pensamiento crítico.

En los estados suramericanos, el fenómeno de internacionalización o "colonización" de la burocracia administrativa en virtud de los compromisos contraídos con los organismos financieros y otras agencias multinacionales, indujo la aplicación de programas que responden a los criterios de planificación del sistema 
capitalista globalizado, antes que a los proyectos de cada país y del conjunto regional para alcanzar sus propias metas de desarrollo e integración.

A comienzos del siglo XXI, la recuperación de los resortes estatales y de la credibilidad del gobierno por los movimientos democráticos y populares que deben afrontar esta pesada herencia no puede cambiar sus condicionamientos de un día para otro, sino a través de una interacción continua y progresiva que asegure la correspondencia de las iniciativas gubernamentales con el interés de los representados.

Los planes de investigación y de intervención social, incluyendo la definición de áreas disciplinarias y metodologías, sin discernir los intereses a que responden, pueden llevar a resultados inconsistentes con los mejores propósitos. Las tendencias "gerencialistas" inspiradas en la gestión empresarial de la mano de obra no van más allá de eficientizar los mismos mecanismos del autoritarismo burocrático. Ante estas evidencias, se trata de superar el conformismo con el statu quo y convertir la profesión de los investigadores en una militancia capaz de plantear alternativas (PAES DE PAULA, MARANHÃO y BARROS, 2009; TENÓRIO, 2009).

Las reformas de los procesos organizacionales requieren una evaluación previa de las condiciones del contexto, en el cual existen con frecuencia carencias elementales y problemas prioritarios que no han previsto los expertos que basan sus recetas en otras realidades. Las innovaciones tecnológicas deben ser apropiadas y filtradas a través de una evaluación que dé cuenta de sus implicancias. Para remover las trabas disfuncionales en la gestión es insuficiente la reproducción mecánica de modelos concebidos en sociedades más estructuradas; es preciso prestar atención a las experiencias de logros y fracasos realizadas de los países vecinos con los que existen evidentes similitudes, y promover la participación y el control popular que permitan ajustar las demandas y las respuestas a las efectivas necesidades (TENÓRIO y MONJE-REYES, 2010).

La lucha por una transformación radical de la sociedad en sentido humanista y liberador aparece hoy bloqueada por la decepcionante caída de los experimentos socialistas en el hemisferio oriental, la disolución de las esperanzas que suscitaba la emergencia de un "tercer mundo" y las fuerzas avasallantes del capitalismo global y su imperialismo financiero y militar; pero la historia no ha terminado. Aunque la evolución de los países suramericanos sigue estando condicionada por la economía de mercado capitalista y por la extranjerización de sus recursos y medios productivos, desde la esfera estatal, recuperada por gobiernos de base popular, es posible contrarrestar sus efectos, regular la distribución de los beneficios y dirigir una estrategia que se sobreponga a las presiones para satelizar nuestros países y reducir nuestras poblaciones a la situación de meros consumidores de las ofertas de los poderes transnacionales: un empeño en el que los instrumentos de gestión de las organizaciones públicas tienen su rol primordial.

\section{En Conclusión}

Actualizar las proposiciones del pensamiento crítico en la forma en que aquí sugerimos, revisando los supuestos teóricos eurocéntricos de las ciencias sociales, implica situar los enfoques analíticos y los proyectos de cambio en la latitud de nuestra comunidad suramericana, en la realidad de nuestros países y sus nudos problemáticos, que son esencialmente idénticos.

La occidentalización de América fue y es un proceso material y cultural conflictivo, en el que han ido aparejadas las distorsiones, la resistencia y la adaptación, produciendo un sedimento de devaluación del orden, de la autoridad y de la ley en todas las capas de la sociedad, en las clases dirigentes y subalternas, que vuelve ilusorios muchos aspectos de la superestructura jurídica formal y exige tener en cuenta sus contradicciones con la cultura vivida.

La causa de la independencia y las luchas de los grandes movimientos populares alimentaron una conciencia nacional y continental, pero estos países han continuado siendo recolonizados por las presiones del sistema 
capitalista mundial, con efectos de enajenación que dificultan el reconocimiento de nuestra identidad y la definición de los objetivos comunes.

El aparato administrativo del Estado, herramienta básica de las políticas nacionales, padece, entre otras rigideces, el lastre del verticalismo autoritario y las rutinas heredadas de su instrumentación antagónica con la sociedad civil, para mantener bajo control a los sectores populares, así como nuevas formas de subordinación a los planes del poder económico global

Los movimientos democratizadores que han llegado a tomar los gobiernos tienen que remodelar de manera creativa las estructuras de la gestión burocrática para responder a las demandas de sus bases sociales. En el ámbito de la enseñanza y la reflexión de los estudios organizacionales, los viejos y nuevos aportes del pensamiento crítico, así como la comunicación entre los intelectuales de nuestros países comprometidos en estas tareas, pueden ser el punto de partida para discutir, elaborar y adelantar las perspectivas de acción orientadas hacia el horizonte de la integración y la plena emancipación de nuestra América.

\section{Referencias}

ARGUMEDO, A. Los silencios y las voces en América Latina: notas sobre el pensamiento nacional y popular. Buenos Aires: Colihue, 2004.

BAGÚ, S. Economía de la sociedad colonial. Ensayo de historia comparada de América Latina. Buenos Aires: El Ateneo, 1949.

BARROS, A. N. de; PÁDUA CARRIERI, A. de. Higher education in Management in Brazil in the 1940s and 1950s: a discussion derived from the cooperation agreements between Brazil and the United States of America. Cadernos EBAPE.BR, v. 11, n. 2, p. 256-273, 2013.

BIAGINI, H. Lucha de ideas en Nuestramérica. Buenos Aires: Leviatán, 2000.

CANESSA DE SANGUINETTI, M. El bien nacer, Limpieza de oficios y limpieza de sangre: raíces ibéricas de un mal latinoamericano. Montevideo: Taurus, 2000.

COLOMBRES, A. América como civilización emergente. Buenos Aires: Catálogos, 2008.

CHUMBITA, H. Jinetes rebeldes. Historia del bandolerismo social en la Argentina. Buenos Aires: Javier Vergara, 2000.

CHUMBITA, H. América en revolución. Breve historia de la emancipación de los países americanos (1776-1830). Rosario: Fundación Ross, 2010.

CHUMBITA, H. Historia crítica de las corrientes ideológicas argentinas. Revolucionarios, nacionalistas y liberales 1806-1898. Buenos Aires: UNLaM-Ross, 2013.

DOS SANTOS, T. Imperialismo y dependencia. México: Era, 1978.

FARIA, J. H. de. Teoria crítica em estudos organizacionais no Brasil: o estado da arte. Cadernos EBAPE.BR, v. 7, n. 1, p. 509-515, 2009.

FERNANDES, F. Dominación y desigualdad: el dilema social latinoamericano. Compiladora Heloísa Fernandes. Bogotá: Siglo del Hombre-CLACSO, 2008.

FERNÁNDEZ RETAMAR, R. Algunos usos de civilización y barbarie. Buenos Aires: Letra Buena, 1993.

FRANK, A. G. Capitalismo y subdesarrollo en América Latina. Buenos Aires: Siglo XXI, 1973. 
GALEANO, E. Las venas abiertas de América Latina. México: Siglo XXI, 1972.

GARCÍA, J. A. La ciudad indiana. Buenos Aires: Ciudad Argentina, 1998.

GUADARRAMA GONZÁLEZ, P. Humanismo en el pensamiento latinoamericano. Tunja: Universidad Pedagógica y Tecnológica de Colombia, 2002.

HERNÁNDEZ ARREGUI, J. J. Imperialismo y cultura, Buenos Aires: Ediciones Hachea, 1957.

MONTIEL, E. El humanismo americano. Perú: Fondo de Cultura Económica, 2000.

OSZLAK, O. Globalización, internacionalización e integración. En: OSZLAK, O. Los miedos de los argentinos: ensayos sociopolíticos y culturales. Buenos Aires: CEDES Espacio, 2006.

PAES DE PAUlA, A. P.; MARANHÃO, C. M. S. de A.; BARROS, A. N. de. Pluralismo, pós-estruturalismo e 'gerencialismo engajado': os limites do movimento critical management studies. Cadernos EBAPE.BR, v. 7, n. 3, p. 392-404, 2009.

PAZ, O. El laberinto de la soledad. Postdata. Vuelta a El laberinto de la soledad. Santiago de Chile: Fondo de Cultura Económica, 1994.

PÉREZ LINDO, A. Mutaciones. Escenarios y filosofías del cambio de mundo, Buenos Aires: Biblos, 1998.

PUIGGRÓS, A. Imperialismo y educación en América Latina. México: Nueva Imagen, 1980.

PUIGGRÓS, R. Los caudillos de la Revolución de Mayo. Buenos Aires: Corregidor, 1971.

PUIGGRÓS, R. Pueblo y oligarquía. México: Patria Grande, 1974.

RAMOS, J. A. Historia de la nación latinoamericana. Buenos Aires: Peña Lillo, 1968.

REIS ROSA, A.; ALCADIPANI, R. A terceira margem do rio dos estudos críticos sobre administração e organizações no Brasil: (re)pensando a crítica a partir do pós-colonialismo. Revista de Administração Mackenzie, v. 14, n. 6, p. 185-215, nov./dez. 2013.

RIBEIRO, D. Las Américas y la civilización. Proceso de formación y causas del desarrollo desigual de los pueblos americanos. Buenos Aires: Centro Editor de América Latina, 1972.

ROIG, A. A. La 'conciencia americana' y su 'experiencia de ruptura'. En: ROIG, A. A. Teoría y crítica del pensamiento latinoamericano. México: Fondo de Cultura Económica, 1981.

ROSENBLAT, Á. La población indígena y el mestizaje en América. Buenos Aires: Nova, 1954.

ROUQUIE, A. Extremo Occidente. Introducción a América Latina. Buenos Aires: Emecé, 1990.

SAGRERA, M. Los racismos en América "Latina". Sus colonialismos externos e internos. Buenos Aires: Astrea, 1974.

SARMIENTO, D. F. Comentarios de la Constitución, 1853. En: Sarmiento, A. B. (Comp.) Obras. Buenos Aires: $1887-$ 1903.

STERN, S. J. (Ed.) Resistance, Rebellion and Consciousness in the Andean Peasant World, 18th to 20th Centuries. Madison: University of Wisconsin Press, 1987.

SUNKEL, O.; PAZ, P. El subdesarrollo latinoamericano y la teoría del desarrollo. Madrid: Siglo XXI, 1973.

TENÓRIO, F. G. Pensamento crítico versus pensamento tradicional. Cadernos EBAPE.BR, v. 7, n. 3, p. 525-526, 2009. 
TENÓRIO, F. G.; MONJE-REYES, P. Ciudadanía, participación y desarrollo local. Santiago de Chile: Arcis, 2010.

TERÁN, O. Positivismo y nación en la Argentina. Buenos Aires: Puntosur, 1987.

TRÍAS, V. Simón Bolívar y el nacionalismo del Tercer Mundo. Montevideo: L. Soares, 1957.

TRÍAS, V. La rebelión de las orillas. Montevideo: Ediciones de la Banda Oriental, 1989.

ZEA, L. Latinoamérica: emancipación y neocolonialismo. Caracas: Tiempo Nuevo, 1971.

ZEA, L. (Comp.). Pensamiento positivista latinoamericano. Caracas: Fondo de Cultura Económica, 1980. 